\title{
Investigation of Al-Fe Aerospace Alloy Laser-Treated with Different Corrosion Characterization Techniques
}

\author{
Moisés Meza Pariona \\ Additional information is available at the end of the chapter
}

http://dx.doi.org/10.5772/57280

\section{Introduction}

One of the non-traditional surface engineering techniques, named laser surface melting (LSM) has attracted growing interest in the recent years for its ability to improving the corrosion performance of aluminum alloys. LSM is a versatile and promising technique that can be used for modifying the surface properties of the material without affecting its bulk properties.

An interesting study was conducted by authors Viejo et al. [1], in which they argue that in the recent years, the aluminum industry has been developed alloys with an increasing damage tolerance in order to finding the demands of the latest and upcoming generations of the commercial aircraft. Particularly the focus was on the Al-Cu-Li alloys (i.e. AA2050 or AA2198 alloys) that have been used in the recent past in the military and space sectors. Their favorable density, strength, toughness, fatigue behavior and thermal stability have made them attractive candidates in applications requiring both high specific strength and an excellent damage tolerance. And differently of the most conventional aerospace alloys, $\mathrm{Al}-\mathrm{Cu}-\mathrm{Li}$ alloys are fusion weldable, which opens up new opportunities in fuselage construction. Nevertheless, as with the others AA2xxx aluminum alloys, Al-Cu-Li alloys can be susceptible to localized and exfoliation corrosion, particularly in chloride-containing environments. Great efforts have been made for producing surface layers that are free from intermetallic precipitates in order to eliminating, or at least reducing, their detrimental effects. For example, it is generally accepted that laser surface melting (LSM) is an useful tool for improving the corrosion resistance of the aluminum alloys, as the result of the formation of the thin melted layers with refined microstructures that are virtually free from intermetallic precipitates and inclusions. Thus, LSM, using $\mathrm{CO}_{2}$ or Nd:YAG laser irradiation, can improve the localized corrosion resistance by modifying the near-surface region through rapid melting and solidification processes. 
The authors Yue et al. [2] have investigated the laser-treated surface using a KrF excimer laser, according to them it was found out that the laser-treated layer consists of the polycrystalline $\alpha-\mathrm{Al}_{2} \mathrm{O}_{3}$ with some undetermined precipitates. They show that the size of $\alpha-\mathrm{Al}_{2} \mathrm{O}_{3}$ crystalline is approximately $5-6 \mathrm{~nm}$. In addition, they have verified by selected-area electron diffraction patterns (SAED) of the laser-melted zone that the structure was of crystalline form. These same authors have examined through the TEM the laser-treated specimen and they have concluded that it did not reveal any coarse second-phase particles, as found in the untreated specimen. However, a stable corrosion film had not been formed at the surface of the untreated specimen due to the presence of numerous second-phase particles, which readily have initiated pitting corrosion and also they have destroyed the integrity of the film. Being that the base the result of this study, the laser-treated layers mainly have consisted of nanocrystalline structures $\alpha$ $\mathrm{Al}_{2} \mathrm{O}_{3}$, which is a chemically stable phase, serves as an effective barrier for protecting the matrix against corrosion attacks.

According to the study of Ryan and Pragnell [3] by the technique of pulsed laser surface melting (PLSM), they have showed that the increase in the corrosion performance of pulsed laser-treated alloys has been widely attributed to the formation of a surface layer that is much more chemically homogenous than to the bulk material. It has generally been assumed that the laser treatment removes second phase particles and partitionless re-solidification of the layer occurs. In order to preventing the formation of a cellular structure throughout the layer on re-solidification and ensure a reasonable chance of obtaining a chemically homogeneous layer, the melt depth is thus restricted to less than $10 \mu \mathrm{m}$ thickness. The success of lasertreatment relies on the aluminum matrix and second phase particles being taken into the liquid phase and mixed with a combination of stirring and diffusion to form a uniform liquid. Ideally, the liquid film should then re-solidify sufficiently quickly to prevent interface instability, trapping the solute in solid-solution. However, due to the short time spent in the liquid phase, it is extremely difficult to achieve an uniform solute distribution. The study of the pulsed laser surface melting of aluminum has concluded that the improvements in corrosive properties are a result of the homogenization of the surface region.

Pariona et al. [4] reported a study of the laser treatment irradiated Al-1.5 wt. \% Fe alloy with $\mathrm{Yb}$-fiber laser beam. This laser treatment without an assisting gas jet was applied to augmenting the production of metal oxides on the laser-treated surface. The laser-treated samples were covered with several weld filets during the remelting process. The results reveal the formation of the weld filet structures with metastable phases and finely dispersed precipitates. The creation of a finely porous layer of the protective coating produced during the rapid remelting process contributed to increasing the corrosion resistance and homogeneous properties of the laser-treated samples when compared with untreated samples. The $\mathrm{Yb}$-fiber laser beam technology applied to the surface treatment of aluminum alloys proved efficient for augmenting their corrosion resistance, thus deserving further investigation for aerospace and automotive applications.

Recently, Pariona et al. [5] have investigated AFM study of the effects of the laser surface remelting on the morphology of Al-Fe aerospace alloys. This work has been focused on the characterization of the surface roughness by AFM technique and cyclic voltammetry of the 
Al-1.5 wt. \% Fe alloy samples subjected to laser surface remelting (LSR). The AFM technique is a highly efficient tool for studying the topographies surface, providing details of the surface on a nanometric scale. This technique enables to the quantification of the peaks and valleys that characterize surface roughness. The analyses were performed on both laser-treated and untreated sanded surfaces, revealing significant differences. The region between weld filets in the laser-treated samples has showed by AFM technique the presence of the lamella-like morphology. The low-angle X-ray diffraction analysis has revealed the presence of the alumina, simple metals and metastable intermetallic phases, which considerably have improved the microhardness of the laser-remelted surfaces. The treated surfaces have showed passivity and stability characteristics by cyclic voltammetry in the electrolytic medium employed in this study. The morphology produced by the laser surface remelting enhanced the microstructure of the Al-Fe alloys by reducing their roughness and increasing their hardness.

Corrosion properties of the Al-1.5 wt. \% Fe alloys as reviewed by Pariona et al. [6] have showed really interesting results, such as, the micrograph analyzed through SEM was found an homogenous microstructure as a result of the rapid solidification. The results obtained in this study have indicated a likely chemically stable phase, i.e. improved passive/oxide film after LSR treatment, which could serve as an effective barrier against corrosion attack in the aggressive sulfuric acidic environments. At an Open circuit potential (OCP) testing, the results have shown that the displacement for more anodic values for the laser-treated specimen when compared to the untreated specimen is attributed to the formation of an aluminum oxide, this oxide is chemically stable and passive that provides an active barrier against the corrosion. The potentiodynamic polarization results have shown that as a result of the laser-treatment, the corrosion current was reduced by as much as ten times and by the cyclic polarization a wide passive region was obtained. As a consequence of these tests the untreated sample is more susceptible to corrosion, while the laser-treated specimen is less susceptible to corrosion. In the cyclic polarization curves of the untreated sample it was observed greater area of hysteresis loop i.e. higher susceptibility to corrosion than to the laser-treated sample, it can therefore be concluded that LSR process indeed has an influence on surface film modification, which results in higher corrosion resistance.

In this paper the laser surface remelting (LSR) was applied in the Al-1.5 wt. \% Fe alloy in order to investigating the treated layer with different corrosion characterization techniques and complementing with other techniques to elucidate the behavior of corrosion. For this purpose, multiple laser weld filets were generated on an entire surface of the samples by LSR technical. Thus, the morphological characteristic of cross-section of the LSR-treated surface was examined and also the existence of different phases in the treated sample was verified. In addition, corrosion testing was carried out, using different techniques to understand the performance of the samples and their stability in the aggressive environment of laser-treated surface in relation to the substrate material. The application possibilities of this technique may be in aeronautic, automotive, energy, electronic, biomedical implant applications, etc. 


\section{Experimental setup}

\subsection{Specimen preparation of Al-1.5 wt. \% Fe}

Usually cylindrical ingot of Al-1.5 wt. \% Fe alloy was prepared from pure raw materials in our studies. Chemical composition of the Al-1.5 wt. \% Fe alloy measured through the technique of florescence (Shimadzu, EDX-700) is shown in Table 1. The casting assembly of solidification experiments consists of water-cooled mold with heat being extracted only from the bottom, promoting vertical upward directional solidification.

\begin{tabular}{cccc}
\hline Al & Fe & $\mathrm{Cu}$ & $\mathrm{Ni}$ \\
\hline 98.347 & 1.545 & 0.068 & 0.04 \\
\hline
\end{tabular}

Reprinted from Applied Surface Science 2013, 276,1, Pariona MM, et al., Influence of laser surface treated on the characterization and corrosion behavior of Al-Fe aerospace alloys, Copyright (2013), with permission from Elsevier [License Number:3176530612877] [6].

Table 1. Chemical composition of the Al-1.5 wt. \% Fe alloy (wt. \% ).

\subsection{Laser surface remelting of the Al-1.5 wt. \% Fe alloy}

The samples were cut, polished and sand-blasted to reduce their surface reflectance for the subsequent laser treatment, which was performed with a $2 \mathrm{~kW}$ Yb-fiber laser (IPG YLR-2000S) operating at wavelength of $1.06 \mu \mathrm{m}$, with an effective focal distance of $160 \mu \mathrm{m}$. The laser beam presents a near Gaussian intensity profile with a spot size of $50 \mu \mathrm{m}$ and the sample surface was positioned $3 \mathrm{~mm}$ out of beam focus and the laser beam diameter was estimated at $560 \mu \mathrm{m}$ on the sample surface. The laser scanning speed was kept at $40 \mathrm{~mm} / \mathrm{s}^{-1}$. The average power of the laser beam was fixed at $600 \mathrm{~W}$ and the power density on the surface of the sample was estimated as $4.8 \times 10^{5} \mathrm{~W} . \mathrm{cm}^{-2}$. This laser treatment without an assisting gas jet was applied to augment the production of metal oxides on the laser-treated surface. The laser-treated samples were covered with several weld filets during the remelting process [4].

\subsection{Phase, microstructure, and elements characterization}

For the metallography characterization of the cross section, small specimens were cut and sanded with 600, 800, 1200 grit SiC sand paper, and polished with colloidal silica in a semiautomatic polishing machine (AROTEC Ind. and Com., Brazil). The micrographs were obtained by optical microscopy (OM, Olympus-BX51).

The low-angle X-ray diffraction (LA-XRD) technique was employed to identify the phases on the laser-treated surface. The profiles were recorded with a scan rate of $2^{\circ}$. $\min ^{-1}$ and an inclination angle of $1.5^{\circ}$, using a Rigaku-ULTIMA IV X-ray diffractometer. 


\subsection{Surface roughness studies}

The atomic force microscopy (AFM) analysis was performed with a Shimadzu SPM-9600 microscope in $400-\mathrm{nm}$ minimum resolution, equipped with a $125 \times 125 \times 7 \mu \mathrm{m}$ piezoelectric scanner operating in contact mode, operating point $1.5 \mathrm{~V}$, integration gain 700 , rate $0.8 \mathrm{~Hz}$, resolution 512x512 pixels. Characteristic of cantilever, Olympus, COD OMCL-TR800PSA-1, resonance frequency $73 \mathrm{KHz}$, spring constant $0.57 \mathrm{~N} / \mathrm{m}$, rectangular shape, thickness $0.8 \mu \mathrm{m}$, probe shape pyramidal, height $2.9 \mu \mathrm{m}$, radius $15 \mathrm{~nm}$, material $\mathrm{SiN}$ and coated with gold. Software used was SPM Manager versio 3.0, Shimatzu Corporation. For this study, a new cantilever was used every time. Analysis were performed on the material without laser treatment and sample sanded ( $\mathrm{SiC} 1200 \#)$ and, as shown in the schema of Fig. 1, on the LSRtreated material on the region on the weld filet (I) and on the region between the weld filets (II).

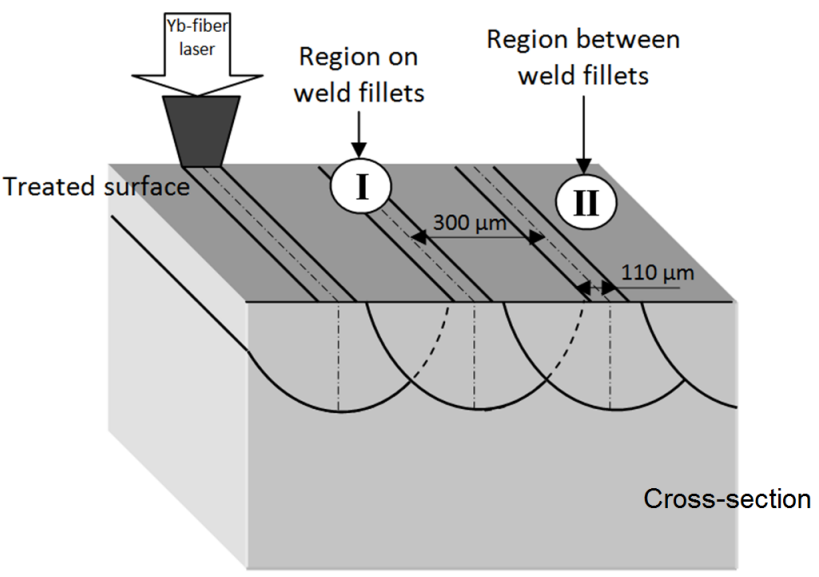

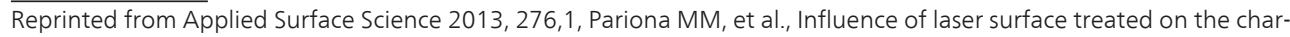
acterization and corrosion behavior of Al-Fe aerospace alloys, Copyright (2013), with permission from Elsevier [License Number:3176530612877] [6].

Figure 1. Laser Surface Remelting process schema showing the weld filets three-dimensional formed by the Yb-fiber laser. I - in the region on the weld filet and II - the region between weld filets.

\subsection{Electrochemical measurements}

Specimens of the untreated and laser-treated material were cut for appropriating the dimensions and then working electrodes were built using epoxy resin. Before the experiments, the untreated $\mathrm{Al}$ alloy was polished with 1200 grit $\mathrm{SiC}$ sand paper, washed with distilled water and dried with absorbent paper. The laser-treated specimens were only washed with distilled water and dried with absorbent paper.

The corrosion tests were performed in 0.1 mol. $\mathrm{L}^{-1}$ of $\mathrm{H}_{2} \mathrm{SO}_{4}$ aqueous aerated solution using potentiostat Autolab - PGSTAT 30 system that was interfaced to a personal computer for controling the experiment and also for collecting data. The temperature was kept at $25 \pm 1{ }^{\circ} \mathrm{C}$ 
during all the experiments using a Brookfield TC-501 thermostat. All the reagents used were analytically pure. Distilled water was used to prepare the aqueous solution.

A three-electrode glass corrosion cell was employed, with a saturated calomel reference electrode (SCE) and a platinum wire with $3.15 \mathrm{~cm}^{2}$ as counter electrode (CE). The reference electrode was connected to a Luggin capillary for promoting the maximum approach of SCE with the working electrode.

The open circuit potential ( $\mathrm{OCP}$ or $\mathrm{E}_{\mathrm{cor}}$ ) was determinated as a function of time, at zero current, after 55 minutes of immersion [7]. The micropolarization test has disturbed the system about $\pm 10 \mathrm{mV}$ of the $E_{\text {cor }}$ while the macropolarization has been $\pm 150 \mathrm{mV}$, with a scan rate of $1 \mathrm{mV} . \mathrm{s}^{-1}$. Cyclic polarization tests have initial scan potentials close to the $\mathrm{E}_{\text {cor }}$, where the electric currents associated to anodic and cathodic processes are equals. The maximum anodic applied potential was $+3.0 \mathrm{~V}$ versus SCE, returning to potentials close to $\mathrm{E}_{\text {cor }}$, with scan rate of $100 \mathrm{mV} / \mathrm{s}^{-1}$.

\section{Results and discussion}

\subsection{Microstructural and phase analysis}

The surface of the Al-1.5 wt. \% Fe specimen treated by LSR is shown by optical microscopy $(\mathrm{OM})$ in Fig. 2. Fig. 2a shows the surface of the specimen with an arrangement of multiple weld filets covering the area. Micro-porosity was observed on the surface of the laser-treated sample [4] and more preferably on the region (I). In addition, the protuberances were observed on this surface, which corresponds to the region between weld filets (II). Fig. $2 \mathrm{~b}$ shows the crosssection of the specimen, where three different regions are observed; the laser-melted zone (LMZ), the heat affect zone (HAZ) and the substrate. The first is characterized by an homogeneous microstructure; according to the study of Ryan and Pragnell [3] by the technique of pulsed laser surface melting (PLSM), the majority of the re-solidified material does not exhibit phase separation between the LMZ and HAZ, this feature was also confirmed by the authors $[6,8,9]$, it is highlighted by dashed yellow lines and while on the substrate are observed grain boundaries.

The meltpool profile not only depends on the energy density but also on the laser beam profile used, which in this case was approximately Gaussian. This beam profile becomes more perceptible in the microstructure at low irradiance and residence times, which was observed in Fig. 2 and this study was confirmed by the authors Chikarakara et al. [10] and these authors also reported that, lower meltpool depths can be advantageous due to their corresponding lower induced thermal stress thus eliminating formation of cracks on the surface. Yue et al. [2] reported that in the solidification of the laser melted zone, a planar solid-liquid interface may prevail, although, this is different from the cellular dendritic structures obtained from the laser surface melting of Al-alloys using $\mathrm{CO}_{2}$ lasers.

LMZ has the characteristic to be homogenous and many micro-porosities are observed on it $[4,6,8]$. Furthermore, LMZ has a higher level of homogeneity relative to the substrate material, meaning that the treatment could be considered an ideal tool for surface [3] and this result was 
coherent with this research. Wang and his collaborators [11] have shown a similar result (Fig. $2 b)$, they reported that the microstructure of the cross-section is characterized by very fine granular grain in the coating and this result was confirmed in this research. In another research of laser treatment of Al alloys, given by Ryan and Pragnell [3], the behavior of homogenous chemical composition was attributed to the distribution of elements as a result of rapid solidification. In addition, low residence time leads to higher cooling rates, producing a more dynamic solidification and allowing the formation of novel phases and more homogeneous microstructures, meaning that apparently useful properties are achieved.
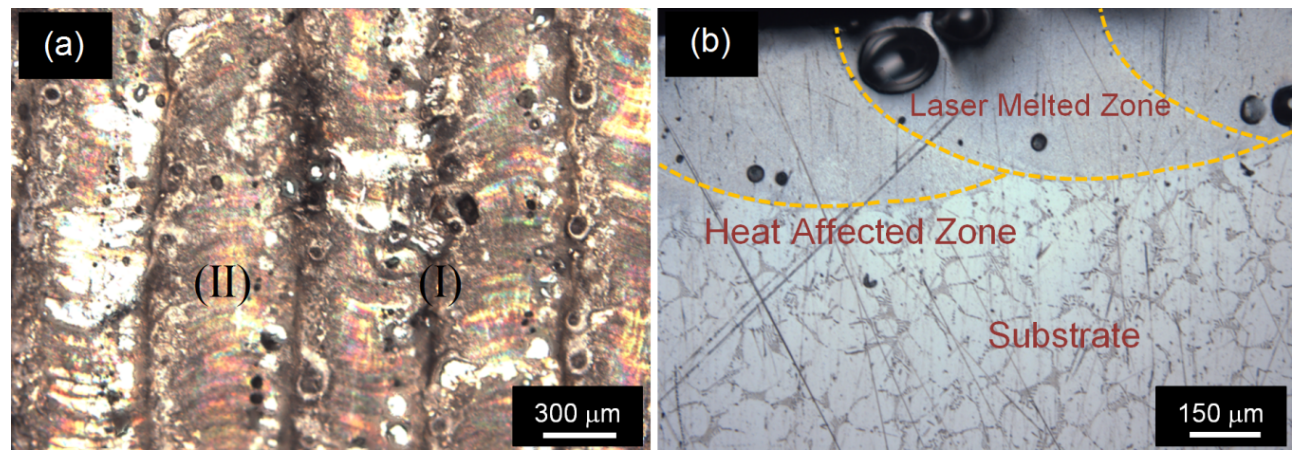

Reprinted from Applied Surface Science 2013, 276,1, Pariona MM, et al., Influence of laser surface treated on the characterization and corrosion behavior of Al-Fe aerospace alloys, Copyright (2013), with permission from Elsevier [License Number:3176530612877] [6].

Figure 2. Specimen morphology of LSR by optical microscopy: (a) the LSR-treated surface of an as-received specimen showing in (I) the region on the weld filets, (II) the region between the weld filets and (b) cross-section of the specimen in relation to the weld filets.

\subsection{X-ray diffraction analysis}

The characterization by low-angle X-ray diffraction (LA-XRD) was made on the laser-treated and untreated specimens and the result is shown in Fig. 3. In this figure two intense peaks around $38^{\circ}$ and $45^{\circ}$ are observed.

In $2 \theta$ equal to $38^{\circ}$ the intensity of the peak of the laser-treated specimen is very elevated, however the peak intensity of the untreated specimen is low. In both samples, the element $\mathrm{Al}$ is present; however, the phases alumina $\left(\mathrm{Al}_{2} \mathrm{O}_{3}\right)$ and iron oxide $\left(\mathrm{Fe}_{2} \mathrm{O}_{3}\right)$ are present in the lasertreated specimen, being both phases of the metastable characteristic. Nevertheless, for $2 \theta$ equal $45^{\circ}$ the peak intensity of the laser-treated specimen is low but for the untreated specimen is high. Furthermore, in both samples in $45^{\circ}$, the phases $\mathrm{Al}$, Fe and $\mathrm{Al}_{13} \mathrm{Fe}_{4}$ eutectic [12] are present and the metastable phases, $\mathrm{Al}_{2} \mathrm{O}_{3}, \mathrm{AlFe}$ and $\mathrm{FeAl}_{2}$ are present only at the peak of the lasertreated specimen. In other angles the intensity of the peaks are despicable.

In the $\mathrm{Al}-\mathrm{Fe}$ alloy the typical phase $\mathrm{Al}_{13} \mathrm{Fe}_{4}$ FCC [12] with eutectic structure occurs in solidification almost in equilibrium. When LSR is applied at the Al-1.5 wt. \% Fe alloy the phase 
mentioned above turns into phases with metastable characteristics, due to the low residence time used in the experiment. That implies in high cooling rates forcing the formation of different phases, allowing very little time for the diffusion producing the equilibrium of the compositions phases [7].

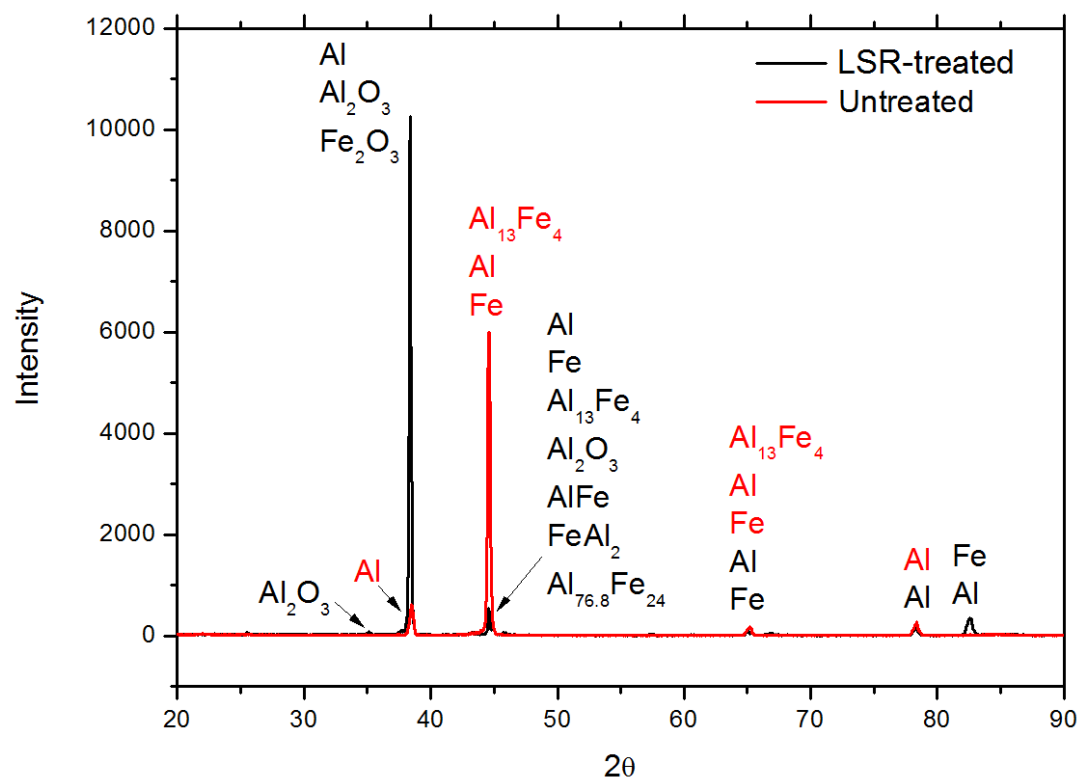

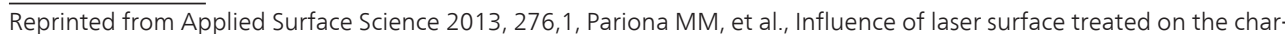
acterization and corrosion behavior of Al-Fe aerospace alloys, Copyright (2013), with permission from Elsevier [License Number:3176530612877] [6].

Figure 3. Low-angle X-ray diffraction (LA-XRD) technique for the untreated and laser-treated specimens.

\subsection{Surface roughness}

One of the advantages of the AFM technique is that it permits being operated in the air, compared to electron microscopy, where the specimens are examined under vacuum conditions causing drying of the specimens and structural alterations [13]. Our aim was to characterise the surface of Al-1.5 wt. \% Fe microstructure that resulted from the LSR treatment in a nanoscale order, in the regions on weld filet (I) and between weld filets (II) and compare these results with the untreated specimen. One of the goals of this research is to enhance the understanding of the $\mathrm{Yb}$-fiber laser beam treatment processing. The mathematical formulas that characterize the morphology of the studied surface by AFM is shown in Table 2. A summary of the image analysis results of the structures that were studied on the various surfaces are shown in Table 3. The measure of the roughness is given frequently by the parameter $R_{a}$. The size of the AFM area used for this study is shown in Figures 4 and 5. 


\begin{tabular}{|c|c|c|}
\hline Parameter & Description & Formula \\
\hline$R_{a}$ & Arithmetic average for absolute values [13] & $\begin{array}{l}\mathrm{R}_{\mathrm{a}}=\frac{1}{N_{x} N_{y}} \sum_{i=1, j=1}^{N_{x} N_{y}}\left|z(i, j)-z_{\text {mean }}\right| \\
\text { where } z_{\text {mean }}=\frac{1}{N_{x} N_{y}} \sum_{i=1, j=1}^{N_{x}^{N N}} z_{i j}\end{array}$ \\
\hline$R_{\mathrm{q}}, \mathrm{R}_{\mathrm{RMS}}$ & Root mean square $[13,14]$ & $\mathrm{R}_{\mathrm{q}}=\sqrt{\frac{1}{N_{x} N_{y}} \sum_{i=1, j=1}^{N_{x}^{N y}}\left(z(i, j)-z_{\text {mean }}\right)^{2}}$ \\
\hline $\mathrm{R}_{\mathrm{v}}$ & Maximum valley depth [14] & $\mathrm{R}_{\mathrm{V}}=\min _{\mathrm{i}} \mathrm{Z}_{\mathrm{i}}$ \\
\hline$R_{p}$ & Maximum peak height [14] & $R_{p}=\max _{i} Z_{i}$ \\
\hline $\mathrm{R}_{\mathrm{z}}$ & $\begin{array}{l}\text { Average distance between the highest peak and } \\
\text { lowest valley in each sampling length [15] }\end{array}$ & $R_{z}=R_{p}+R_{v}$ \\
\hline$R_{\text {zjis }}$ & $\begin{array}{l}\text { Japanese Industrial Standard for } \mathrm{R}_{\mathrm{z}} \text { based on the five } \\
\text { highest peaks and lowest valleys over the entire } \\
\text { sampling length. [13] }\end{array}$ & $\begin{array}{l}\mathrm{R}_{\mathrm{zjis}}=\frac{1}{5} \sum_{i=1}^{5} R_{p i}-R_{v i} \\
\text { where } \mathrm{R}_{\mathrm{pi}} \text { and } \mathrm{R}_{\mathrm{vi}} \text { are, respectively, the } \mathrm{i}^{\text {th }} \text { highest } \\
\text { peak and lowest valley }\end{array}$ \\
\hline
\end{tabular}

Reprinted from Applied Surface Science 2013, 276,1, Pariona MM, et al., Influence of laser surface treated on the characterization and corrosion behavior of Al-Fe aerospace alloys, Copyright (2013), with permission from Elsevier [License Number:3176530612877] [6].

Table 2. Description of the parameters that characterize the morphology of the surface studied by AFM [13-15].

\begin{tabular}{lccc}
\hline AFM parameter & On weld fillets (I) & Between weld fillets (II) & Untreated \\
\hline Area $\left[\mu m^{2}\right]$ & 1600 & 1600 & 1600 \\
\hline$R_{\mathrm{a}}[\mathrm{nm}]$ & 178 & 211 & 142 \\
\hline$R_{\mathrm{z}}[\mathrm{nm}]$ & 1714 & 2097 & 1889 \\
\hline$R_{\mathrm{zjis}}[\mathrm{nm}]$ & 852 & 1025 & 917 \\
\hline$R_{\mathrm{q}}[\mathrm{nm}]$ & 236 & 266 & 190 \\
\hline$R_{\mathrm{p}}[\mathrm{nm}]$ & 936 & 1101 & 752 \\
\hline$R_{\mathrm{v}}[\mathrm{nm}]$ & 779 & 995 & 1137 \\
\hline
\end{tabular}

Reprinted from Applied Surface Science 2013, 276,1, Pariona MM, et al., Influence of laser surface treated on the characterization and corrosion behavior of Al-Fe aerospace alloys, Copyright (2013), with permission from Elsevier [License Number:3176530612877] [6].

Table 3. Quantitative results of the morphology of the surface studied by AFM technique.

Fig. 4 corresponds to the result of the morphological characterization of the region II with $\mathrm{R}_{\mathrm{a}}=178 \mathrm{~nm}$ (Table 2). Fig. 4a shows the result in 3-D, where it can be observed the surface topography that characterizes the different valleys and peaks. In Fig. $4 \mathrm{~b}$ the rough surface in 
2-D is observed, which displays a type of lamellae with different orientations covering the whole considered area.

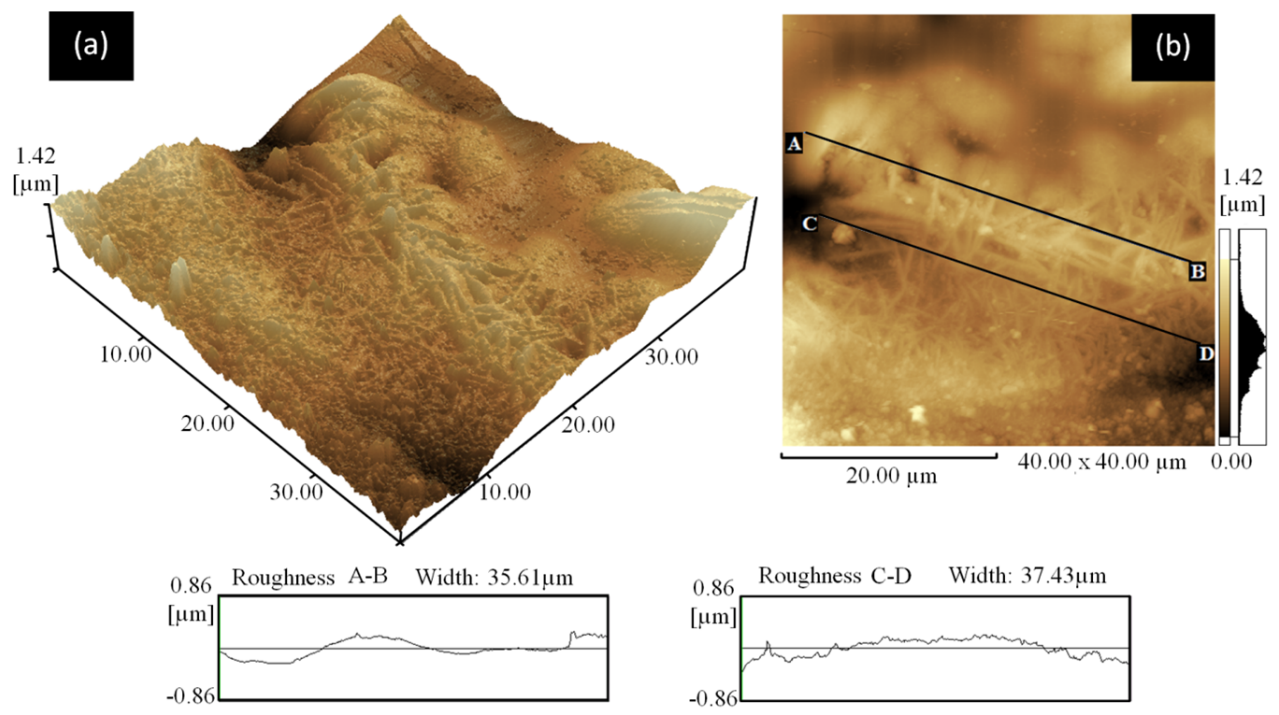

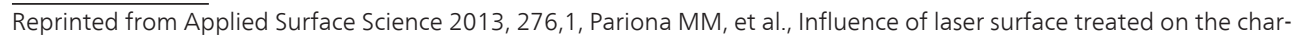
acterization and corrosion behavior of Al-Fe aerospace alloys, Copyright (2013), with permission from Elsevier [License Number:3176530612877] [6].

Figure 4. Image displays surface mapping for Al-1.5 wt. \% Fe specimen around between weld filets (II): (a) visualization in 3D-AFM and (b) visualization in 2D-AFM.

Fig. 5 shows the result by AFM on region I with $R_{a}=211 \mathrm{~nm}$. Fig. 5a shows the result in 3-D, where it can be noticed that all parameters corresponding to this area are greater than the ones corresponding to the region II. This fact may be justified due to the greater concentration of nano-porosity that was observed between weld filets (II) according to the micrograph of Fig. 2. In Fig. 5b, the 2-D surface, a not homogeneous feature is shown because of the increased presence of defects in the area, although, in this part it was not possible to observe lamellae, as in the previous case.

The morphology result for the untreated material is shown in Fig. 6 with $R_{a}=142 \mathrm{~nm}$. In Fig. $6 a$ the morphological characteristic is shown in $3-\mathrm{D}$, and Fig. $6 \mathrm{~b}$ in $2-\mathrm{D}$, where some nanodefects on the surface are noticed. According to the results in Table 3, the roughness parameter $R_{a}$ was lower for the untreated sample than that of the laser-treated sample. This is associated with the presence of many nano-porosities, especially on region I and a certain vaulted shape of the specimen in the region II (Fig 2a). Also, the maximum peak $\left(R_{p}\right)$ observed in the untreated sample was lower than on the treated specimen, but however, the depth of the maximum valley $\left(R_{v}\right)$ was higher than the treated. 

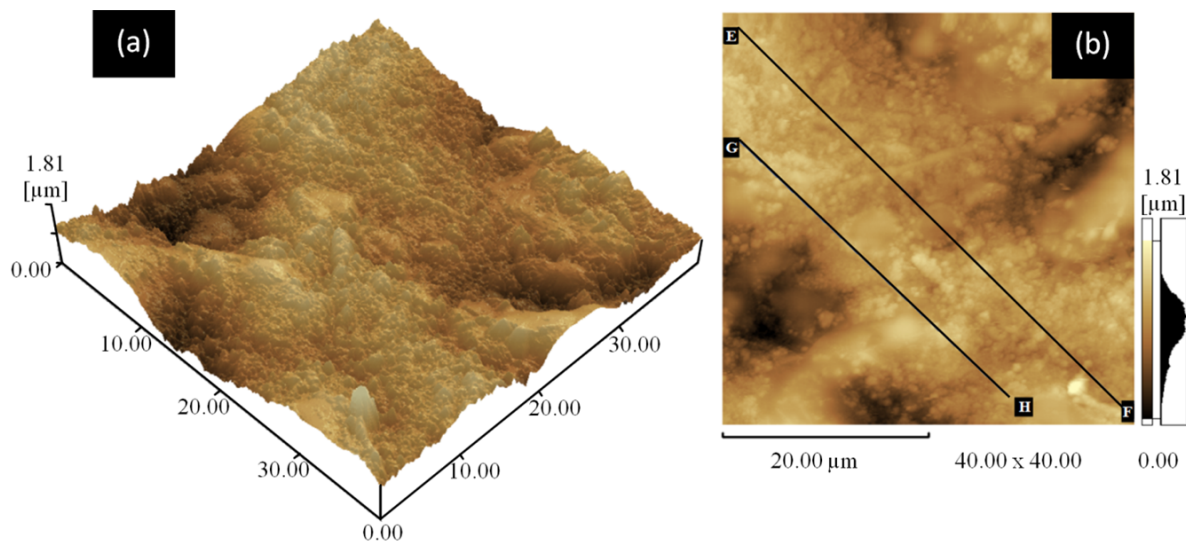

$20.00 \mu \mathrm{m}$

$40.00 \times 40.00$

0.00
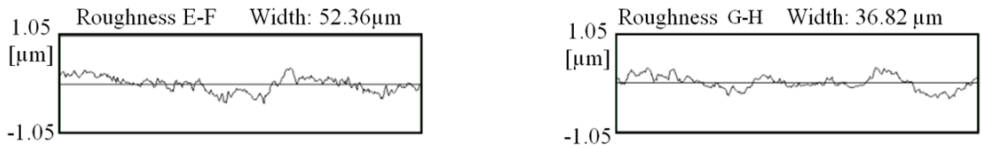

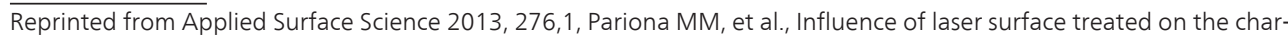
acterization and corrosion behavior of Al-Fe aerospace alloys, Copyright (2013), with permission from Elsevier [License Number:3176530612877] [6]

Figure 5. Images of the surfaces of Al-1.5 wt. \% Fe around on weld filets (I): (a) visualization in 3D-AFM and (b) visualization in 2D-AFM.
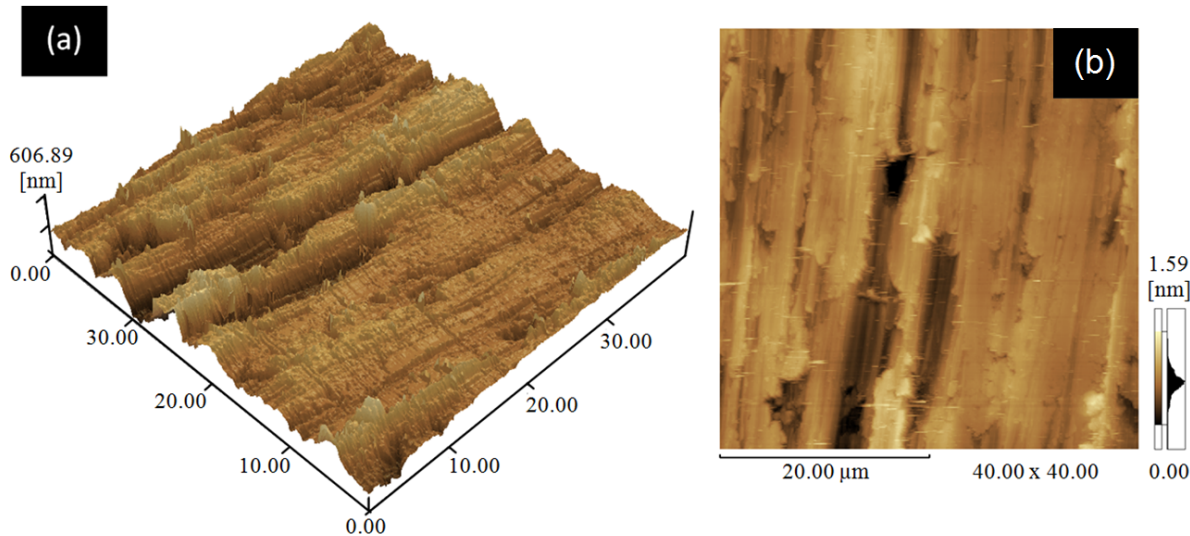

Reprinted from Applied Surface Science 2013, 276,1, Pariona MM, et al., Influence of laser surface treated on the characterization and corrosion behavior of Al-Fe aerospace alloys, Copyright (2013), with permission from Elsevier [License Number:3176530612877] [6].

Figure 6. AFM surface mapping of the untreated specimen, sanded with 1200\#: (a) visualization in 3D and (b) visualization in 2D. 
In this study it was verified that AFM is a suitable technique for examining the surface morphology of the laser-treated alloy [5]. Therefore, the AFM technique is related to the flatness requirement of the investigated area, because, through this characteristic it is possible to quantify the nano-roughness of the surface $[5,6]$. Thus in this work it was verified that the surface roughness of $\mathrm{Al}-1.5 \mathrm{wt}$. \% Fe laser-treated is greater in relation to the untreated specimen. In the LSR-treated specimen the decrease in roughness in region II, it is mainly attributed to a more homogeneous morphology showing a lamella-like morphology covering the entire surface. Furthermore, the nano-roughness characteristics could be closely related to the melting characteristics and energy density. An increase in residence time of the laser beam resulted in an increased depth of processing $[6,8]$.

In this study was varied the speed of the cantilever, as a result has been observed that for high speed of this device, the area of the samples analyzed by AFM showed little definition of the surface, however, for low speed cantilever the surface of the samples showed a better definition, therefore, at this work was used to the speed of $0.8 \mathrm{~Hz}$, which is a relatively slow speed. In this work were done also tests for the cantilever in contact mode and non-contact, being that the best definition of the surface was for the contact mode, because this cantilever was more appropriate for material with characteristic surface rather uniform and with high hardness. Also, in this study were performed analysis by AFM in different areas and noncontact, being that the best definition of the surface was for the contact mode, in this study were performed analysis by AFM in different areas of the surface, but, the characteristics of the lamellae between weld filets were always found [5,6]. Precisely, these characteristic and surface quality were assessed by different corrosion tests, the result is shown in the following section. The study done by the analysis using the AFM technique was necessary to complement the research done by corrosion.

\subsection{Electrochemical studies}

\subsubsection{Cyclical polarization for untreated specimen}

Cyclic voltammetry is an efficient and versatile electrochemical technique, used in the study of systems that involve oxidation-reduction reactions in electrolytic solutions, through the analysis of the behavior of anodic and/or cathodic current as a function of the applied potential. This technique allows obtaining the information on the electrode processes, such as, the reversibility of the electrochemical reactions and the determination of kinetic and thermodynamic parameters. Furthermore, the cyclic voltammetry was utilized for comprehension of the oxidation process of the laser-treated and as well as the untreated specimens in a sulphuric acid environment.

Fig. 7 shows two different cyclic polarizations for the untreated specimen in $\mathrm{H}_{2} \mathrm{SO}_{4}$ aerated solution. The first cycle starts in $-0.50 \mathrm{~V}$ until the most anodic value $+0.90 \mathrm{~V}$, versus SCE, returning to $-0.50 \mathrm{~V}$. During the anodic scan, there is a current increase near the $-0.15 \mathrm{~V}$, associated with the aluminum dissolution, followed by the formation of an aluminum oxide $\left(\mathrm{Al}_{2} \mathrm{O}_{3}\right)$ film on the sanded substrate. The anodic current rapidly has increased until approximately $+0.30 \mathrm{~V}$, followed by a smaller growth rate until $+0.90 \mathrm{~V}$; it is characterized as 
a region of thickening of the oxide film. After the inversion potential, there is a sharp drop of the anodic current up to $+0.60 \mathrm{~V}$ and, thereafter, reaching low values of currents in potential close to $-0.50 \mathrm{~V}$.

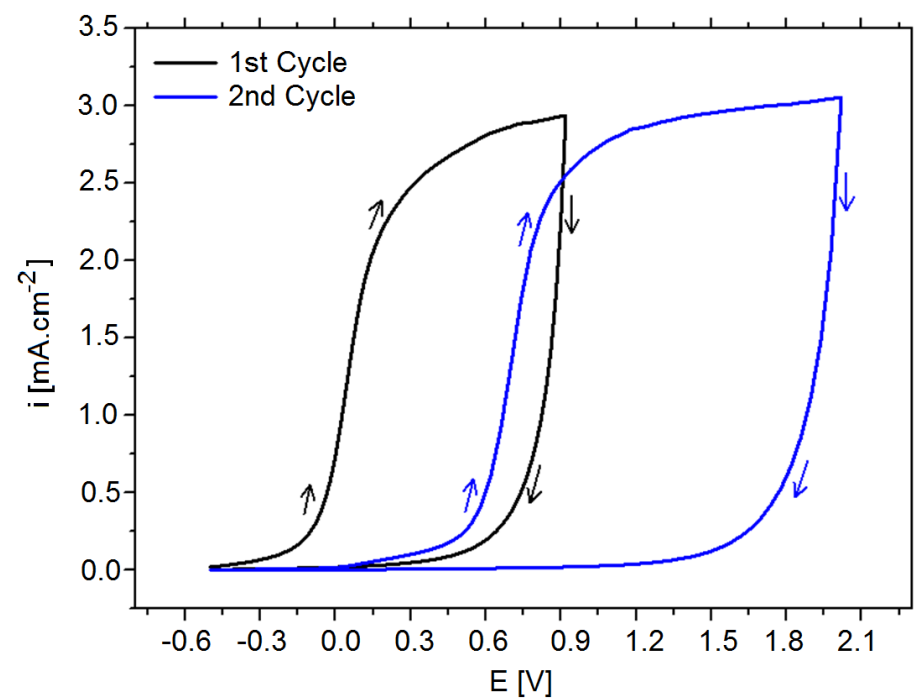

Reprinted from Applied Surface Science 2013, 276,1, Pariona MM, et al., Influence of laser surface treated on the characterization and corrosion behavior of Al-Fe aerospace alloys, Copyright (2013), with permission from Elsevier [License Number:3176530612877] [6].

Figure 7. Cyclic polarization curves for untreated specimens, at $100 \mathrm{mV} \cdot \mathrm{s}^{-1}$, in 0.1 mol.L-1 aerated solution of $\mathrm{H}_{2} \mathrm{SO}_{4}$ : (a) First scan cycle and (b) second scan cycle.

During the process, two chemical reactions are associated with the anodic potential scan. The first step is the electrochemical aluminum dissolution, followed by chemical reaction of $\mathrm{Al}^{+3}$ ions with the water molecules in the acid solution interface metal/solution, i.e. according to the reactions [17]:

$$
\begin{gathered}
\mathrm{Al}_{(\mathrm{M})} \rightarrow \mathrm{Al}_{(\mathrm{M} / \mathrm{sol})}^{+3}+3 \mathrm{e}^{-} \\
2 \mathrm{Al}_{(\mathrm{M} / \mathrm{sol})}^{+3}+3 \mathrm{H}_{2} \mathrm{O}_{(\mathrm{M} / \mathrm{sol})} \rightarrow \mathrm{Al}_{2} \mathrm{O}_{3(\mathrm{Ox})}+6 \mathrm{H}_{(\mathrm{Ox} / \mathrm{sol})}^{+}
\end{gathered}
$$

Where M, M/sol, Ox e Ox/sol correspond to metal, interface metal/electrochemical solution, oxide layer and interface oxide/solution, respectively.

The authors Zankara et al. [18] and Santos et al. [19] showed that the aluminum oxides formed in acid electrolytes presents uniformly nanostruturated forms, like nanotubes with cylindrical 
pores, which the size orthe thickness depend on the electrical charge applied to the electrochemical system, and through this nanotubes there is $\mathrm{Al}^{+3}$ ions diffusion.

Finished the first cycle (Fig. 7), the electrode was maintained in the solution for 5 minutes to restore the equilibrium conditions on the interface electrode/solution, while keeping the system in open circuit potential (zero current). Right after, the second cycle began with -0.50 $\mathrm{V}$ to $+2.0 \mathrm{~V}$ where the anodic current of aluminum dissolution starts increasing from $+0.30 \mathrm{~V}$, being around $600 \mathrm{mV}$ more anodic when compared to the first cycle of potential scan; after de potential inversion, from $+1.50 \mathrm{~V}$, the values of anodic current density goes back to the same ones of the first cycle. The displacement for more positive potential values is associated with the growth of a second layer of an $\mathrm{Al}_{2} \mathrm{O}_{3}$ film over than the one obtained during the first cycle of potential scan. In the second cycle, the anodic current grows with lower rates from $+1.20 \mathrm{~V}$, due to the thickening of the $\mathrm{Al}_{2} \mathrm{O}_{3}$ film, and this current density is close to $3.0 \mathrm{~mA} . \mathrm{cm}^{-2}$ in that potential; although, in the inversion potential scan $(+2.0 \mathrm{~V})$, the anodic current diminished.

\subsubsection{Cyclical polarization for untreated and laser-treated specimens}

In this section a comparative study was carried out of the cyclic polarization to laser-treated and untreated samples with the purpose of studying the behavior of these materials in the same electrolyte solution. Fig. 8a shows the comparison between the cyclic polarizations curves for the laser-treated and untreated specimens, in aerated solution of $\mathrm{H}_{2} \mathrm{SO}_{4} 0.1$ mol. $\mathrm{L}^{-1}$, at $25^{\circ} \mathrm{C}$.
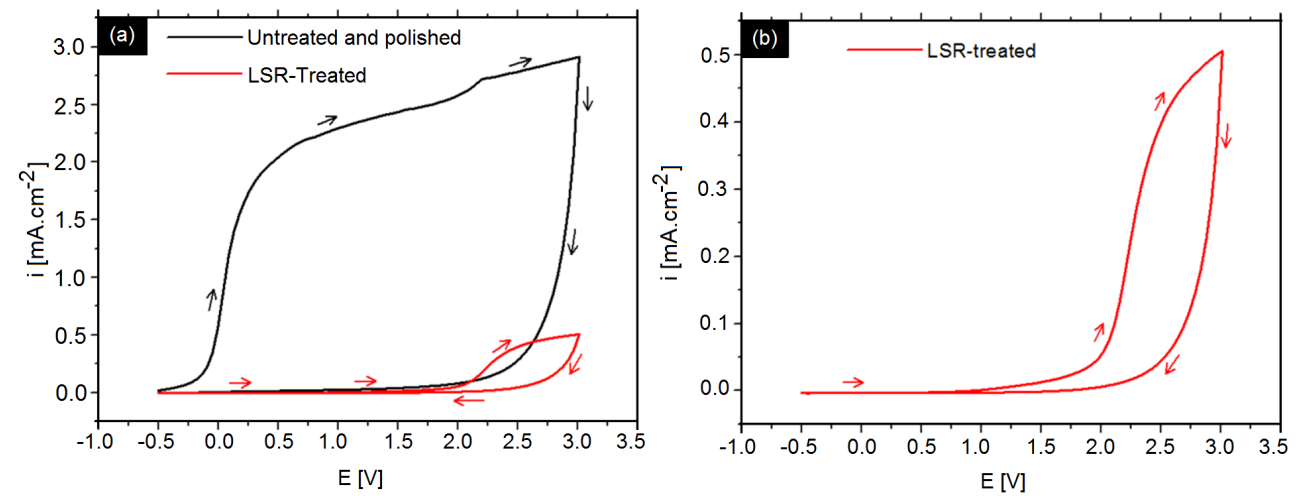

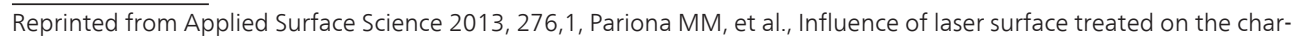
acterization and corrosion behavior of Al-Fe aerospace alloys, Copyright (2013), with permission from Elsevier [License Number:3176530612877] [6].

Figure 8. Cyclic polarization curves (a) untreated and laser-treated specimens and (b) magnification for the laser-treated specimen.

In Fig. 8a, the black line shows the cyclic polarization curve of the untreated specimen carried out in the range of potential between $-0.50 \mathrm{~V}$ to $+3.0 \mathrm{~V}$ versus SCE. It was noticed that the anodic current increases in the vicinity of $-0.15 \mathrm{~V}$ and a change of curvature in the graphic occurs in $+0.5 \mathrm{~V}$, as it was also obtained in the first cycle of the cyclic polarization in Fig. 7. This change 
in the curvature is probably related to the reactions given by equations (1) and (2). Next to the potential of $+2.10 \mathrm{~V}$ is observed, again, an increase in the current that can be associated to the thickening of the $\mathrm{Al}_{2} \mathrm{O}_{3}$ film, meanwhile, it can be related to the oxidation of the intermetallic phase $\mathrm{Al}_{3} \mathrm{Fe}$ observed in $\mathrm{Al}-1.5 \mathrm{wt}$. \% Fe alloy [4]. After the reversal potential, the dissolution current sharply decreases to $+2.0 \mathrm{~V}$, reaching low values of anodic current.

The cyclic polarization curve of Fig. 8b, is the same of Fig. 8a which was magnified forbettering the visualization. It is observed that the anodic current increases from the potential of $+1.75 \mathrm{~V}$, this can be associated with the growth of the aluminum oxide film and/or Al-Fe phases on the surface of laser-treated sample, which is constituted by different phases, such as $\mathrm{Al}_{2} \mathrm{O}_{3}, \mathrm{Fe}_{2} \mathrm{O}_{3}$, $\mathrm{Al}, \mathrm{AlFe}, \mathrm{Al}_{13} \mathrm{Fe}_{4}$ among others, this was confirmed by X-ray (Fig.3). A very similar point of view was reported in [4].

In the magnification Fig. 8b, the anodic potential that corresponds to the beginning of the oxidation on the surface of the LSR-treated was displaced to $+1.90 \mathrm{~V}$. In the anodic scan the elevation of the current starts at $-0.15 \mathrm{~V}$ in the untreated sample, however, in the LSR-treated sample begins at $+1.75 \mathrm{~V}$, thus in the range of $-0.5 \mathrm{~V}$ to $+1.75 \mathrm{~V}$ the current is kept almost constant, showing the passivity of the LSR-treated sample. Thereby, during polarization as much forward as in return for this specimen, passivation had occurred, and it had also appeared in a spanning region over 2.25 V. Therefore, the surface of the LSR-treated has proved to be an effective way for achieving the passivation in this electrolytic environment, indicating the stability of the passive film against the dissolution. The authors Qu et al. [20] and Ng et al. [21] have observed a similar result for the $\mathrm{Mg}$ and $\mathrm{Ti}$ alloys, respectively. In addition, the authors Viejo et al. [1] have concluded that the change in the electrochemical behavior has been associated with the formation of a relatively uniform melted layer with an improved passivity properties in a magnesium alloy.

Nevertheless, the anodic current density in the inversion potential for the laser-treated alloy is $0.5 \mathrm{~mA} . \mathrm{cm}^{-2}$, as can be seen in Fig. $8 \mathrm{~b}$. This value is lower than the one observed for the untreated alloy, which presented a current of $2.92 \mathrm{~mA} \cdot \mathrm{cm}^{-2}$. These results show that the lasertreated alloy surface has a different chemical composition and its own morphology, preoriented by surface, because of the formed $\mathrm{Al}_{2} \mathrm{O}_{3}$ film.

In Fig. 8 the hysteresis loops are observed, being greater for untreated sample. This characteristic is related to the susceptibility to attacked by the corrosion. Seah et al. [22] reported that the absence of any hysteresis loop demonstrates clearly the capability of the titanium to a quickly repassivate. Also Shih et al. [23] has pointed out that in general, the larger the area of the hysteresis loop, implies a greater susceptibility to pitting corrosion. Once again, it has been proved that the LSR-treatment was effectively improved corrosion resistance properties.

\subsubsection{Open circuit potential (OCP) for laser-treated and untreated specimens}

The nature of the oxide layer of $\mathrm{Al}_{2} \mathrm{O}_{3}$ formed during the LSR-treatment may have influence over the corrosion potential, as well as in polarization resistance $\left(R_{p}\right)$ and in Tafels constant $\beta_{a}$ and $\beta_{c}$ associated with the anodic and cathodic processes, respectively, which occurs at the 
interface understood by the laser-treated surface and the electrolyte solution. Moreover, the effect of laser-treatment in the Al-1.5 wt. \% Fe alloy may directly affect the corrosion resistance of this material in the solution of $\mathrm{H}_{2} \mathrm{O}_{4}$ and these was verified in this study.

Fig. 9 shows the behavior of the OCP of laser-treated and untreated alloys as a function of exposure time in an acid medium. There was a shift in the initial potential of the untreated sample from $-0.670 \mathrm{~V}$ to $-0.720 \mathrm{~V}$ after approximately 750 seconds followed by stabilization of $\mathrm{E}_{\text {cor }}$ in $-0.706 \mathrm{~V}$, after 55 minutes in OCP. About the same period of time, the laser-treated alloy suffers a displacement of initial potential of $-0.530 \mathrm{~V}$ until stabilization in $-0.606 \mathrm{~V}$.

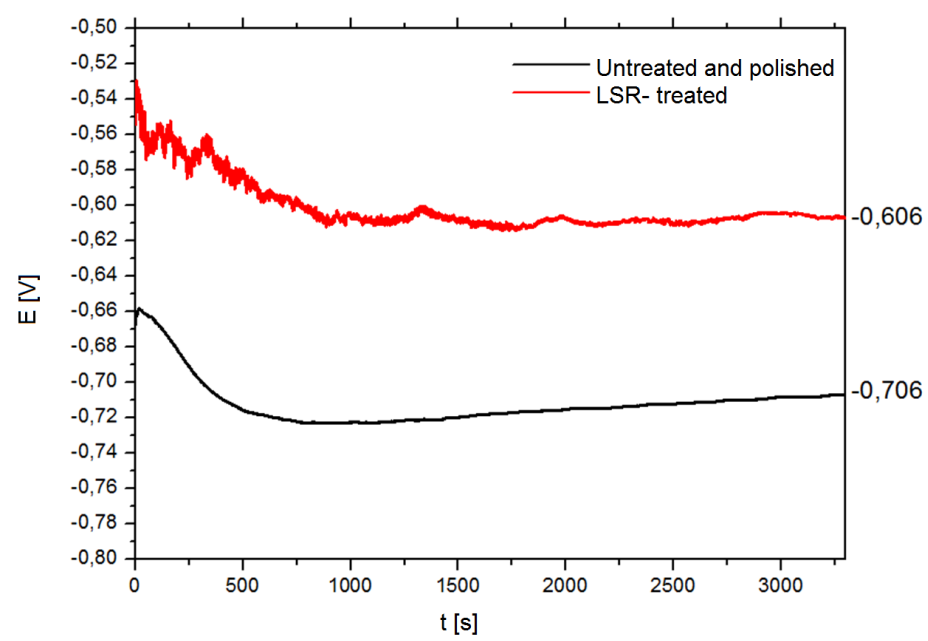

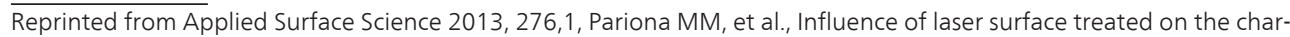
acterization and corrosion behavior of Al-Fe aerospace alloys, Copyright (2013), with permission from Elsevier [License Number:3176530612877] [6].

Figure 9. OCP versus saturated calomel electrode (SCE) in aerated solution of $\mathrm{H}_{2} \mathrm{SO}_{4} 0.1 \mathrm{~mol}$. $\mathrm{L}^{-1}$.

The displacement of $100 \mathrm{mV}$ for more anodic values in the corrosion potential for the lasertreated material is attributed to the formation of an aluminum oxide, this oxide is chemically stable that provides an active barrier against the corrosion of Al-1.5 wt. \% Fe alloy. A similar result was attained by authors Viejo et al. [1] for aluminum alloy using the LSM technique.

\subsubsection{The polarization resistance of laser-treated and untreated specimens}

The micropolarization of $\pm 10 \mathrm{mV}$ around corrosion potential promotes a perturbation in the equilibrium potential, giving the appearance of an anodic and cathodic current in the electrochemical cell circuit. This technique of the electric current versus applied potential was conducted to the laser-treated and untreated samples, and the result is shown in Fig. 10. The inverse slope of the line in Fig. 10 allows to determining the polarization resistance of the system that is associated with the charge transfer processes in the interface metal/oxide/ 
electrolyte solution. The values of $17.8 \mathrm{~K} \Omega$ for the laser-treated alloy against $1.4 \mathrm{~K} \Omega$ for the untreated alloy showed that the metal/solution interface is different and the polarization resistance has direct impact on corrosion rates of these surfaces in sulfuric acid. Therefore, the microstructure generated by the laser-treatment definitely influences the polarization resistance $\left(R_{p}\right)$ of the alloy.

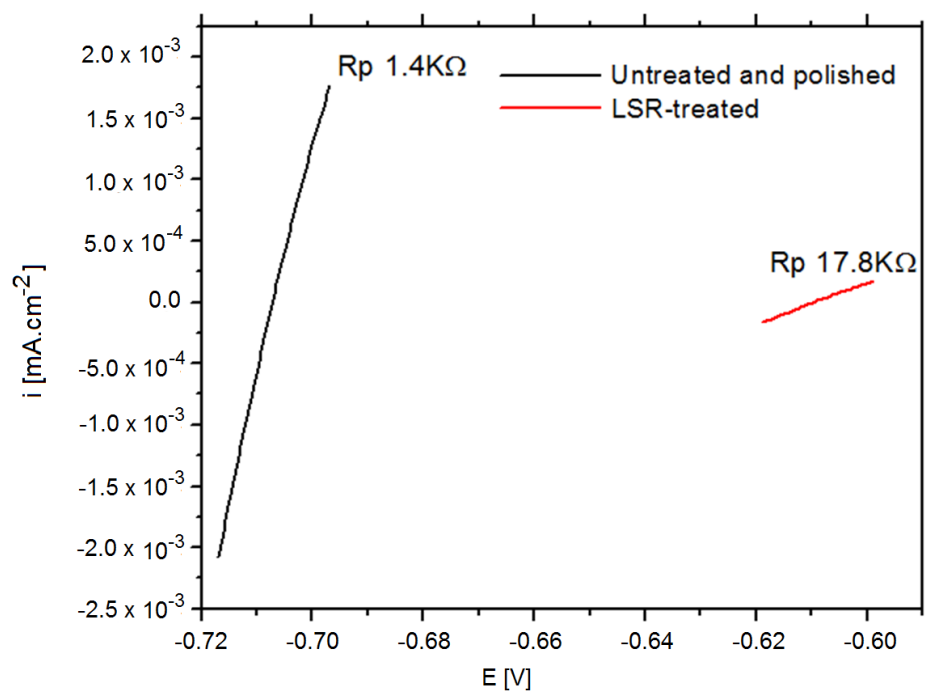

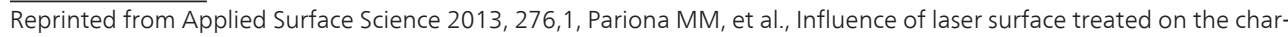
acterization and corrosion behavior of Al-Fe aerospace alloys, Copyright (2013), with permission from Elsevier [License Number:3176530612877] [6].

Figure 10. Micropolarization of $\pm 10 \mathrm{mV}$ near of $\mathrm{E}_{\text {cor }}$ versus $\mathrm{SCE}$ in aerated solution of $\mathrm{H}_{2} \mathrm{SO}_{4} 0.1$ mol.L-1 , with scan rate of $1 \mathrm{mV} \cdot \mathrm{s}^{-1}$.

\subsubsection{The corrosion current $\left(i_{\text {cor }}\right)$ for laser-treated and untreated specimens}

The potentiodynamic polarization curves for the Al-1.5 wt. \% Fe alloy in 0.1 mol.L-1 of $\mathrm{H}_{2} \mathrm{SO}_{4}$, aerated at $25^{\circ} \mathrm{C}$ and with a scan rate of $1 \mathrm{mV} . \mathrm{s}^{-1}$ is shown in Fig. 11, varying from cathodic potentials at $-150 \mathrm{mV}$ toward $\mathrm{E}_{\mathrm{cor}}$ and more positive to $+150 \mathrm{mV}$. According to this curves, the anodic $\left(\beta_{\mathrm{a}}\right)$ and cathodic $\left(\beta_{\mathrm{c}}\right)$ constants of Tafel are determinate.

Fig. 11 shows the behavior of $\log$ (i) as a function of applied potentials over the alloy. At the point of inversion of cathodic to anodic current during the dynamic scanning, it represents approximately the corrosion potentials obtained after 55 minutes of immersion in OCP (Fig. 9). The different values of $\beta_{\mathrm{a}}$ and $\beta_{\mathrm{c}}$ are associated with the electrochemical reaction of oxidation and reduction over the surfaces of working electrodes. 


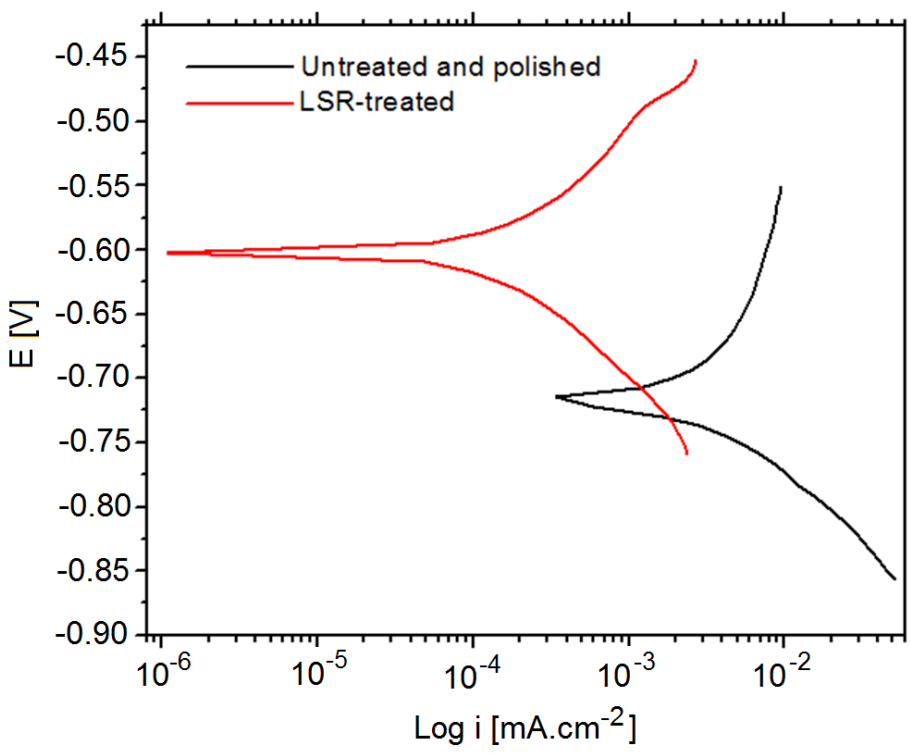

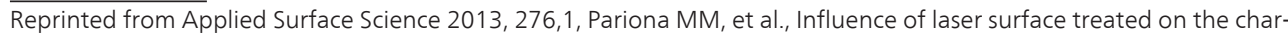
acterization and corrosion behavior of Al-Fe aerospace alloys, Copyright (2013), with permission from Elsevier [License Number:3176530612877] [6].

Figure 11. Potentiodynamic polarization for untreated and laser-treated alloys in the interval of $\pm 150 \mathrm{mV}$ around $\mathrm{E}_{\text {cor }}$ versus SCE.

The corrosion current $\left(i_{\text {cor }}\right.$ ) or the corrosion rate were calculated from the values of $R_{p}, \beta_{a}$ and $\beta_{\mathrm{c}}$ appling Stern-Geary equation [20]. The main electrochemical parameters were calculated, and are shown in Table 4.

\begin{tabular}{|c|c|c|c|c|c|c|}
\hline Condition & $E_{\text {cor }}(V)$ & $R_{p}(K \Omega)$ & $\begin{array}{c}\beta_{\mathrm{a}} \\
\left(\mathrm{V} \cdot \mathrm{dec}^{-1}\right)\end{array}$ & $\begin{array}{c}\beta_{\mathrm{c}} \\
\left(\mathrm{V} \cdot \mathrm{dec}^{-1}\right)\end{array}$ & $\begin{array}{c}\text { icor } \\
\left(\mu \mathrm{A} . \mathrm{cm}^{-2}\right)\end{array}$ & $\begin{array}{c}\text { Corrosion rate } \\
\left(\mathrm{mm} . \mathrm{year}^{-1}\right)\end{array}$ \\
\hline Laser-treated & 0.606 & 7.8 & 0.161 & 0.110 & 11.7 & 0.1 \\
\hline Untreated & 0.706 & 1.4 & 0.432 & 0.131 & 119.8 & 1.3 \\
\hline \multicolumn{7}{|c|}{$\begin{array}{l}\text { Reprinted from Applied Surface Science 2013, 276,1, Pariona MM, et al., Influence of laser surface treated on the } \\
\text { characterization and corrosion behavior of Al-Fe aerospace alloys, Copyright (2013), with permission from Elsevier } \\
\text { [License Number:3176530612877] [6]. }\end{array}$} \\
\hline
\end{tabular}

Table 4. Electrochemical parameters calculated for the Al-1.5 wt. \% Fe alloy for laser-treated and untreated specimens in an aerated solution of $\mathrm{H}_{2} \mathrm{SO}_{4} 0.1$ mol. $\mathrm{L}^{-1}$ at $25^{\circ} \mathrm{C}$.

Table 4 shows the range of variation of the $\beta_{\mathrm{c}}$ for the untreated and laser-treated samples that is around $20 \mathrm{mV} \cdot \mathrm{dec}^{-1}$ which occurs in the linear region of the cathodic branch of Fig. 11. This process is associated with hydrogen reduction reaction over the working electrode. However, 
the $\beta_{\mathrm{a}}$ value had an expressive variation around $270 \mathrm{mV} \cdot \mathrm{dec}^{-1}$, it is referring to the linear region of anodic branch. This indicates that the oxidation process of the alloy is affected by the conditions of the electrodes.

Therefore, the value of the corrosion rate of laser-treated alloy is smaller than that of the untreated alloy in about 12 to 14 times. This occurs due to the presence of an oxide layer and because of the other phases produced by heat treatment with laser, turning this layer more resistant to the corrosion when compared to the oxide film formed on the surface of the untreated alloy during the interval of stabilization of the corrosion potential.

In this research, a great improvement in the performance of corrosion was confirmed on the laser-treated alloy, which showed a greater range of passivity and very high polarization resistance, a lower area of the hysteresis loop, and the corrosion rate was much smaller in relation to the untreated alloy. Through the analysis of the laser-treated sample by different techniques the following factors could have been contributed to a good performance of protection against corrosion: the micrograph presented an homogeneous microstructure; the surface roughness was lower by AFM; the presence of a lamellar structure were detected by AFM; the existence of several metastable phases by LA-XRD and non-existence of secondphase particles. Besides, in all the corrosion testing a reduction of current density was found in the laser-treated alloy; this result was confirmed by authors Viejo et al. [1]. They concluded that LSM-treated specimens exhibited a general reduction in current density over most of the examined potential range. They still have extended their research and reported that even after LSM; the alloy experienced a reduction in anodic and cathodic activities, mainly associated with the formation of a relatively uniform melted layer with passive properties and the diminished presence of intermetallic precipitates. They have also verified that LSM enhanced the intergranular corrosion resistance of the AA2050-T8 alloy.

The parameters that can have a strong influence on the increase in the corrosion performance are the homogenous microstructural and non-existence of the second-phase particles characteristics. To respect several authors have verified these characteristics. The authors Chikarakara et al. [10] used the energy dispersive X-ray spectroscopy (EDS) technique analysis and they demonstrated that laser surface modification produced a more homogenous chemical composition of the alloying elements compared to the untreated bulk metal. The authors Yue et al. [2] examined the laser-treated specimen with TEM and concluded that it did not reveal any coarse second-phase particles, as were found in the untreated specimen. However, a stable corrosion film had not been formed at the surface of the untreated specimen due to the presence of numerous second-phase particles, which readily have initiated pitting corrosion and have destroyed the integrity of the film. The laser-treated layers consisted mainly of the nanocrystalline structures $\alpha-\mathrm{Al}_{2} \mathrm{O}_{3}$, which is a chemically stable phase and serves as an effective barrier to protect the matrix against corrosion attacks [2], possibly in this work these phases nanocrystalline structure facilitates the formation of lamellar structures identified by MFA, these lamellars provide in turn better behavior of surface treated against corrosion. According to the study of Ryan and Pragnell [3] by pulsed laser surface melting (PLSM) technique, they have showed that the increase in the corrosion performance of the pulsed laser-treated alloys has been widely attributed to the formation of a surface layer that is much more chemically 
homogenous than the bulk material. They assumed that the laser treatment removes second phase particles and partitionless re-solidification of the layer occurs. Redistribution of alloying elements within the treated titanium alloys is also known to improve pitting corrosion resistance due to preferential corrosion attack prevention [3]. In addition, Chikarakara and their collaborators [10] pointed out that a secular martensite structure enhances the materials wear and corrosion resistance.

\section{Conclusions}

Laser surface remelting (LSR) without protective coating with a $2 \mathrm{~kW}$ Yb-fiber laser (IPG YLR-2000S) was applied on Al-1.5 wt. \% Fe alloy to investigate the corrosion behavior in an aerated $\mathrm{H}_{2} \mathrm{SO}_{4}$ solution $\left(0.1 \mathrm{~mol} . \mathrm{L}^{-1}\right)$. The results obtained permit the following conclusions:

1. An homogenous microstructure was verified as a result of the rapid solidification,

2. The LSR technique was successfully established to improve the surface properties of Al1.5 wt. \% Fe alloys in relation to the substrate alloy.

3. The results obtained in this study indicate a more likely chemically stable phase, i.e. improved passive/oxide film after LSR treatment, which could serve as an effective barrier against corrosion attack in an aggressive sulfuric acidic environments,

4. At an OCP testing, the results have shown that the displacement for more anodic values for the laser-treated specimen when compared to the untreated specimen is attributed to the formation of an aluminum oxide, this oxide is chemically stable and passive that provides an active barrier against the corrosion,

5. The potentiodynamic polarization results have shown that as a result of the lasertreatment, the corrosion current was reduced by as much as ten times and by the cyclic polarization a wide passive region was obtained. As a consequence of these tests the untreated sample is more susceptible to corrosion, while the laser-treated specimen is less susceptible to corrosion,

6. In the cyclic polarization curves of the untreated sample it was observed greater area of hysteresis loop i.e. higher susceptibility to corrosion than for the laser-treated sample,

7. It can therefore be concluded that LSR process indeed has an influence on surface film modification, which results in higher corrosion resistance.

\section{Acknowledgements}

The authors acknowledge the financial support of the Brazilian research funding agencies CNPq (National Council for Scientific, Technological Development), AF (Araucária Foundation), and FINEP (Research and Projects Financing Agency). We also thank CLABMU/ PROPESP UEPG for the analyses. 


\section{Author details}

Moisés Meza Pariona

Address all correspondence to: mmpariona@uepg.br

Engineering and Materials Science, State University of Ponta Grossa (UEPG), Ponta Grossa, Brazil

\section{References}

[1] A.E. Coy, F. Viejo, F.J. Garcia-Garcia, Z. Liu, P. Skeldon, G.E. Thompson, Effect of excimer laser surface melting on the microstructure and corrosion performance of the die cast AZ91D magnesium alloy, Corros. Sci. 52 (2010) 387-397.

[2] T.M. Yue, L.J. Yan, C.P. Chan, C.F. Dong, H.C. Man, G.K.H. Pang, Excimer laser surface treatment of aluminum alloy AA7075 to improve corrosion resistance, Surf. Coat. Technol. 179 (2004) 158-164.

[3] P. Ryan, P.B. Prangnell, Grain structure and homogeneity of pulsed laser treated surfaces on Al-aerospace alloys and FSWs, Mater. Sci. Eng. A, 479 (2008) 65-75.

[4] M.M. Pariona, V. Teleginski, K. dos Santos, S. Machado, A.J. Zara, N.K. Zurba, R. Riva, Yb-fiber beam effects on the surface modification of Al-Fe aerospace alloy obtaining weld filet strutures, low fine porosity and corrosion resistence; Surf. Coat. Technol. 206 (2012) 2293-2301.

[5] M.M. Pariona, V. Teleginski, K. dos Santos, E. L. R. dos Santos, A. C. de Lima, A.J. Zara, R. Riva. AFM study of the effects of laser surface remelting on the morphology of Al-Fe aerospace alloys. Materials Characterization, (2012) 64-76.

[6] M.M. Pariona, V. Teleginski, K. dos Santos, A.A.O.C. de Lima, A. J. Zara, K. T. Micene,, R. Riva. Influence of laser surface treated on the characterization and corrosion behavior of Al-Fe aerospace alloys. Applied Surface Science. 276 (2013) 76-85.

[7] ASTM G59-97. Standard Test Method for Conducting Potentiodynamic Polarization Resistance Measurements, 2009.

[8] M. Ulmeanua, F. Jipa, C. Radu, M. Enculescu, M. Zamfirescu, Large scale microstructuring on silicon surface in air and liquid by femtosecond laser pulses, Appl. Surf. Sci. 258 (2012) 9314- 9317.

[9] F. Bertelli, E.S. Meza, P.R. Goulart, N. Cheung, R. Riva, A. Garcia, Laser remelting of Al-1.5 wt \% Fe alloy surfaces: Numerical and experimental analyses, Opt. Laser Eng. 49 (2011) 490-497. 
[10] E. Chikarakara, S. Naher, D. Brabazon, High speed laser surface modification of Ti6Al-4V, Surf. Coat. Technol. 206 (2012) 3223-3229.

[11] A.H. Wang, H.B. Xia, W.Y. Wang, Z.K. Bai, X.C. Zhu, C.S. Xie, YAG laser cladding of homogenous coating onto magnesium alloy, Mater. Lett. 60 (2006) 850-853.

[12] Thermo Calc software, Stockholm, Sweden, 2011.

[13] A. Daskalova,, S. Bashirb, W. Husinsky, Morphology of ablation craters generated by ultrashort laser pulses in dentin surfaces: AFM and ESEM evaluation, Appl. Surf. Sci. 257 (2010) 1119-1124.

[14] J. Podskocova, D. Chorvat-Jr, G. Kollarokova, I. Lacik, Characterization of polyelectrolyte microcapsules by confocal laser scanning microscopy and atomic force microscopy, Laser Phys. 15 (2005) 545-551.

[15] U. Khandey, Optimization of surface roughness, material removal rate and cutting tool flank wear in turning using extended taguchi approach, Master thesis, Mechanical Engineering, National Institute of Technology Rourkela, India, 2010.

[16] ISO 4287 - 1997 Geometrical Product Specifications (GPS) - Surface Texture: Profile Method-Terms, Definitions and Surface Texture Parameters.

[17] A. Santos, L. Vojkuvka, J. Pallanés, J. Ferré-Borrull, L.F. Marsal, In situ electrochemical dissolution of the oxide barrier of porous anodic alumina fabricated by hard anodization, J. Electroanal. Chem. 632 (2009) 139-142.

[18] L. Zaraka, G. D. Sulka, J. Szeremeta, M. Jaskula, Porous anodic alumina formed by anodization of aluminium alloy ( AA1050) and high purity aluminium; Electrochim. Acta 55 (2010) 4377-4386.

[19] A. Santos, P. Formentin, J. Ferré-Borrull, J. Pallanés, L.F. Marsal, Nanoporous anodic alumina obtained without protetive oxide layer by hard anodization; Mater. Lett. 67 (2012) 296-299.

[20] Q. Qu, J. Ma, L. Wang, L. Li, W. Bai, Z. Ding, Corrosion behaviour of AZ31B magnesium alloy in $\mathrm{NaCl}$ solutions saturated with $\mathrm{CO}_{2}$, Corros. Sci. 53 (2011) 1186-1193.

[21] K.W. Ng, H.C. Man, T.M. Yue, Characterization and corrosion study of NiTi laser surface alloyed with $\mathrm{Nb}$ or Co, Appl. Surf. Sci. 257 (2011) 3269-3274.

[22] K. H. W. Seah, R. Thampuran, S. H. Teoh, The influence of pore morphology on corrosion, Corros. Sci. 40 (1998) 547-556.

[23] C.-C Shih, C.-M. Shih, Y.-Y. Su, L. H. J. Su, M.-S. Chang, S.-J. Lin, Effect of surface oxide properties on corrosion resistance of 316L stainless steel for biomedical applications, Corros. Sci. 46 (2004) 427-441. 